\title{
Synthesis and identification of an important metabolite of AKB-48 with a secondary hydroxyl group on the adamantyl ring
}

J akob Wallgren, Svante Vikingsson, Anders J ohansson, Martin J osefsson, Henrik Green, Johan Dahlén, Xiongyu Wu and Peter Konradsson

The self-archived version of this journal article is available at Linköping University Electronic Press:

http:// urn.kb.se/ resolve?urn=urn:nbn:se:liu:diva-137391

N.B.: When citing this work, cite the original publication.

Wallgren, J., Vikingsson, S., J ohansson, A., J osefsson, M., Green, H., Dahlén, J., Wu, X., Konradsson, P., (2017), Synthesis and identification of an important metabolite of AKB-48 with a secondary hydroxyl group on the adamantyl ring, Tetrahedron Letters, 58(15), 1456-1458.

https:// dx.doi.org/ 10.1016/j.tetlet.2017.02.077

Original publication available at:

https://dx.doi.org/ 10.1016/j.tetlet.2017.02.077

Copyright: Elsevier

http://www.elsevier.com/

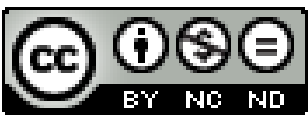




\title{
Synthesis and identification of an important metabolite of AKB-48 with a secondary hydroxyl group on the adamantyl ring
}

\author{
Jakob Wallgren ${ }^{\mathrm{a}}$, Svante Vikingsson ${ }^{\mathrm{b}}$, Anders Johansson ${ }^{\mathrm{a}}$, Martin Josefsson ${ }^{\mathrm{a}, \mathrm{c}}$, Henrik Green ${ }^{\mathrm{b}, \mathrm{c}}$, \\ Johan Dahlén ${ }^{\mathrm{a}}$, Xiongyu Wu ${ }^{\mathrm{a}^{*} \text {, Peter Konradsson }}{ }^{\mathrm{a}}$ \\ a Department of Physics, Chemistry and Biology, Linköping University, Sweden \\ ${ }^{\mathrm{b}}$ Division of Drug Research, Department of Medical and Health Sciences, Faculty of Health Sciences, Linköping University, Sweden \\ ${ }^{c}$ Department of Forensic Genetics and Forensic Toxicology, National Board of Forensic Medicine, Linköping University, Sweden
}

\section{ARTICLE INFO}

\section{ABSTRACT}

\section{Article history:}

Received

Received in revised form

Accepted

Available online

Keywords:

Adamantane

AKB-48

Synthetic cannabinoid

Metabolite

Biomarker
Studies on the metabolism of bioactive substances containing the adamantyl moiety have shown that hydroxylation is likely to occur at a tertiary carbon of adamantane. Herein, we report the synthesis and identification of one major metabolite of AKB-48, a new illicit psychoactive substance with a hydroxyl group at a secondary carbon of the adamantyl ring.

\section{Introduction}

Adamantane is an important moiety in many bioactive substances with a broad spectrum of biological activities. ${ }^{1}$ Current approved therapeutic agents containing the adamantyl moiety range from remedies for Influenza A, Herpes simplex and Acne vulgaris to treatments for Parkinsonism, Alzheimer's disease and type II diabetes mellitus medicines (Vildaglitin, Saxagliptin). Adamantane is also a common building block in new psychoactive substances (NPS), for example AKB-48, 5FAKB-48, APICA and AB001.

Investigations regarding the metabolism of bioactive substances containing the adamantyl moiety have been extensively carried out. ${ }^{3}$ Interestingly, most reports show that the tertiary carbons of the adamantyl moiety are much more prone to oxidation than the secondary carbons unless more than two tertiary carbons are already substituted. For example, 1-amino-3hydroxyadamantane was the only detected metabolite of amantadine. ${ }^{4}$ To the best of our knowledge, there are no reports regarding adamantane containing bioactive substances that exclusively produce a metabolite with a hydroxyl group on a secondary carbon of the adamantyl moiety.

AKB-48, which contains the adamantane moiety, belongs to a family of synthetic cannabinoids that has gained increased popularity as a substitute to cannabis abuse in recent years. Challenges in detecting synthetic cannabinoids are largely due to their fast in vivo metabolism, together with a lack of knowledge concerning their metabolism. The limited access to reference substances and optimized detection methods for these substances in urine are also of concern. Several studies have been conducted on the metabolism of AKB-48 using LC-QTOF-MS to analyse the culture media of human liver microsomes or hepatocytes. The metabolite with a single hydroxyl group on the adamantyl moiety was found to be a major metabolite with an ambiguous structure (Fig. 1), ${ }^{5}$ making it a good candidate for use as a biomarker for AKB-48 intake. This necessitated identification of the exact position of the hydroxyl group, requiring the synthesis of relevant reference substances. Although isolation and identification of metabolites present in urine samples would also work, such an approach is less appropriate as it requires large quantities of samples and extensive animal experiments. ${ }^{3}$ This makes the synthesis of metabolites more applicable in the battle against the rapidly growing illegal drug market.

\section{Results and discussion}

Adamantine 1 was oxidized using concentrated $\mathrm{H}_{2} \mathrm{SO}_{4}$ and $\mathrm{HNO}_{3}$ at $10{ }^{\circ} \mathrm{C}$ to give 3-hydroxy-adamantine 2 in $74 \%$ yield, which was coupled with 3-indazole-carboxylic acid to selectively form amide 3 .

\footnotetext{
* Corresponding author.

Email address: xiongyu.wu@liu.se
} 

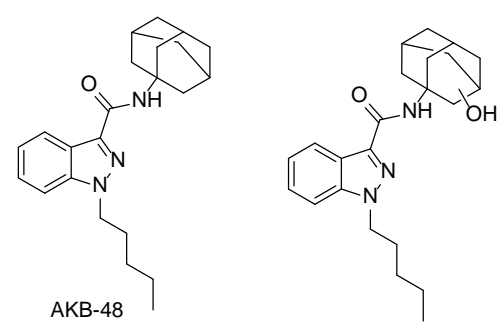

Fig. 1. AKB-48 and its major metabolite with a single hydroxyl group on the adamantyl moiety.

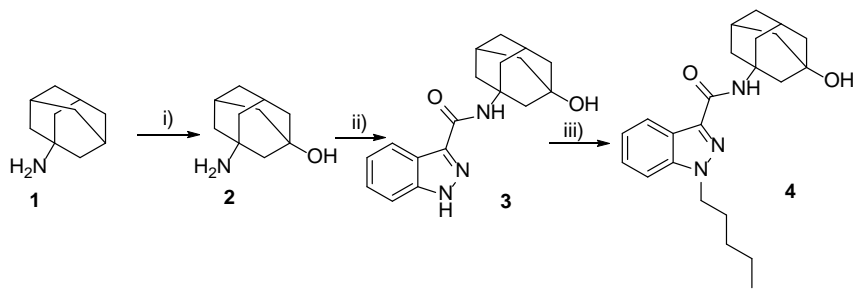

Scheme 1. i) conc. $\mathrm{H}_{2} \mathrm{SO}_{4}$, conc. $\mathrm{HNO}_{3}, 2$ h at $10{ }^{\circ} \mathrm{C}, 74 \%$; ii) TBTU, $1 \mathrm{H}$ indazole-3-carboxylic acid, $\mathrm{Et}_{3} \mathrm{~N}$, THF, rt, overnight, 81\%; iii) 1bromopentane, $t$-BuOK in THF/DMF (5:1), rt overnight, $90 \%$.

Compound $\mathbf{4}$ was obtained after the alkylation of $\mathbf{3}$ with bromopentane in an overall yield of $54 \%$ (Scheme 1). According to the literature method, ${ }^{7}$ the hydroxyl group of compound 5 was converted into an amine group via a Ritter reaction, followed by hydrolysis with $\mathrm{HCl}$ (aq) under microwave irradiation. The resulting crude product was coupled with 3-indazole-carboxylic acid to give compound $\mathbf{6}$. This ketone was alkylated and reduced to give two isomers, 8 and $\mathbf{9}$, in an overall yield of $\sim 8 \%$ and $4 \%$, respectively, over five steps (Scheme 2). The yield of the final step was low due to the difficulty of separating the two isomers. Their structures were elucidated using 1D and 2D NMR (ESI).

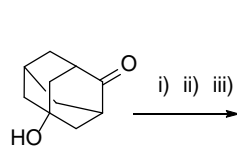

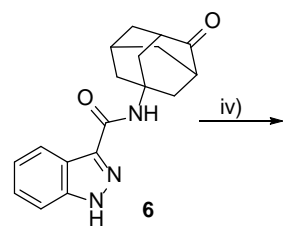

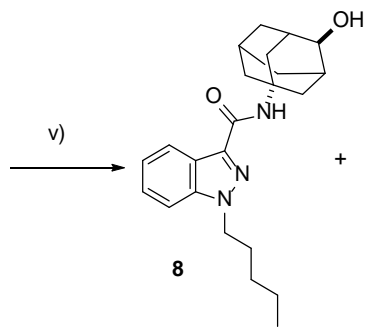

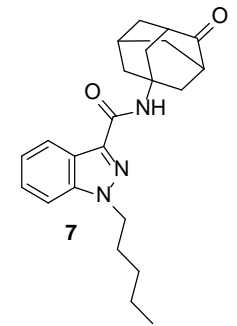

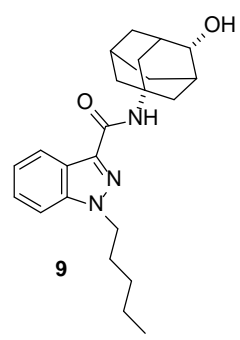

Scheme 2. i) $\mathrm{CH}_{3} \mathrm{CN}, \mathrm{BF}_{3} \cdot \mathrm{Et}_{2} \mathrm{O}$, TFA; ii) conc. $\mathrm{HCl}$ (aq), $150{ }^{\circ} \mathrm{C} \mathrm{MW}$ irradiation, $1 \mathrm{~h}$; iii) TBTU, $1 H$-indazole-3-carboxylic acid' $\mathrm{Et}_{3} \mathrm{~N}$, THF, rt, overnight, 30\% over three steps; iv) 1-bromopentane, $t$-BuOK, DMF/THF (1:5), rt, overnight, 72\%; v) $\mathrm{NaBH}_{4}, \mathbf{8}, 36 \%$ and 9, $20 \%$.

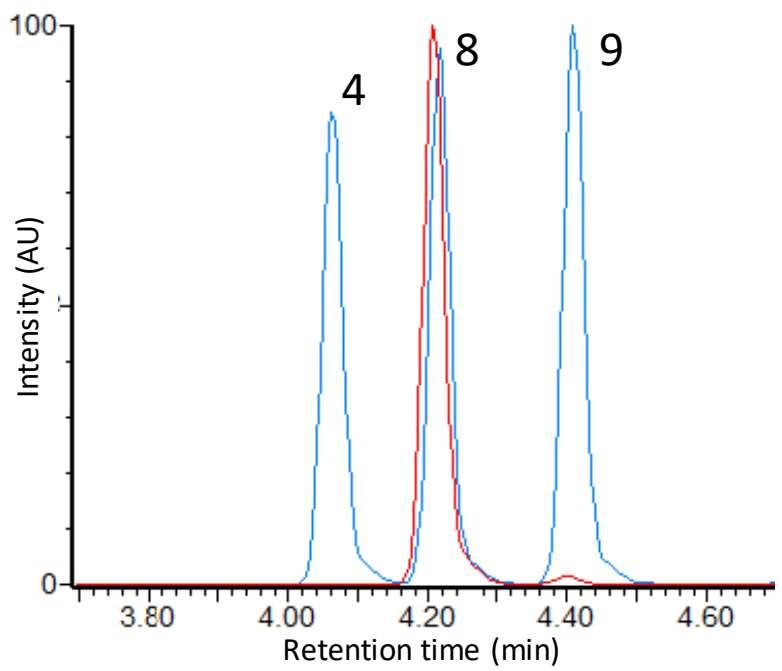

Fig. 2. Analysis of reference materials from compounds 4, 8 and 9 (blue trace), and a urine sample (red trace) by LC-QTOF-MS.

The NPS are often screened using LC-HRMS in forensic toxicology laboratories. During routine LC methods applied at the National Board of Forensic Medicine (RMV), the three potential metabolites $\mathbf{4 ,} 8$ and $\mathbf{9}$ co-eluted. A structured method development process was successfully applied to establish an LC method, enabling the separation of these compounds. In this method, an LC gradient from 26 to $67 \%$ MeCN in $10 \mathrm{mM}$ ammonium acetate on a $100 \times 2.1 \mathrm{~mm}$ Cortecs UPLC C18 column (Waters) over 7.5 min was applied. Using this method, compound $\mathbf{8}$ was found to be the target metabolite (Fig. 2), which can be used as a biomarker for detection of AKB-48 in urine sample.

\section{Conclusion}

In conclusion, we report the straightforward synthesis and identification of an important metabolite of AKB-48 with a single hydroxyl group on a secondary carbon of the adamantyl moiety. The presence of this metabolite in urine samples could therefore act as a biomarker to potentially reveal the abuse of AKB-48. The study also indicates another important, more general, metabolic picture of the adamantyl moiety, namely exclusive metabolism of the adamantyl moiety on a secondary carbon. Furthermore, these results highlight the importance of having access to all the potential metabolites. Without such a set of reference substances, it could be difficult to obtain accurate metabolism results of bioactive molecules containing the adamantyl moiety.

\section{Acknowledgments}

Financial support from the National Board of Forensic Medicine in Sweden is gratefully acknowledged. The authors would like to thank Anna Åstrand for her assisting in LC-QTOFMS analyses.

\section{A. Supplementary data}

Supplementary data associated with this article can be found, in the online version, at http://dx.doi.org/10.1016/j.tetlet.2017.02. 077 . 


\section{References}

1. (a) Lamoureux G, Artavia, G. Curr Med Chem. 2010;17:2967; (b) Zoidis, G, Kolocouris N, Naesens L, De Clercq E. Bioorg Med Chem. 2009;17:1534;

(c) Wang JJ, Lee JY, Chen YC, Chen YT, Chi CW. Int J Oncol. 2006;28:1003;

(d) Park JS, Phee SD, Jung WH, et al. Eur J Pharmacol. 2012;691:19;

(e) Vennerstrom JL, Arbe-Barnes S, Brun R, et al. Nature 2004;430:900;

(f) Chakrabarti JK, Hotten TM, Sutton S, Tupper DE. J Med Chem. 1976;19:967;

2. (a) Gatch MB, Forster M. J Behav Pharmacol. 2015;26:460;

(b) Uchiyama N, Kawamura M, Kikura-Hanajiri R, Goda Y.

Forensic Toxicol. 2012;30:114;

(c) Jankovics PT, Váradi AS, Tölgyesi LS, Lohner S, NémethPalotás JL, Balla JZ. Forensic Sci Int. 2012;214:27;

3. (a) Su H, Boulton DW, Barros A, et al. Drug Met Disp. 2012;40: 1345

(b) Kajbaf M, Rossato P, Barnaby JR, Pellegatti M. Xenobiotica 1998;28:167; (c) Nakada N, Oda K. Xenobiotica 2015;45:757;

(d) Rubio FR, Fukuda EK, Garland WA. Drug Met Disp. 1988; 16:773;

(e) Su H, Boulton DW, Barros Jr A, et al. Drug Met Disp. 2012; 40:1345

(f) Zhou L, Alker A, Ruf A, et al. Bioorg Med Chem Lett. 2008; 18:1555;

(g) Fura A, Khanna A, Vyas V, et al. Drug Metab Dispos. 2009; 37:1164;

4. Wesemann W, Schollmeyer W. Sturm, G. Arzneim Forsch. 1977; 27:1471;

5. (a) Gandhi AS, Zhu M. Pang S, et al. AAPS J. 2013;15:1091;

(b) Holm NB, Nielsen LM, Linnet K. AAPS J. 2015;17:1237;

(c) Vikingsson S, Josefsson M, Green H. J Anal Toxicol. 2015;39:426;

6. Lavrova LN, Indulen MK, Ryazantseva GM, Korytnyi VS, Yashunskii VG. Pharm Chem J. 1990;24:35;

7. Averina NV, Borisova GS, Zefirova ON, Selyunina EV, Zyk NV, Zefirov NS. Russ J Org Chem. 2004;40:497; 


\title{
Synthesis and Identification of an Important Metabolite of AKB-48 with a Secondary Hydroxyl Group on the Adamantyl Ring
}

\author{
Jakob Wallgren ${ }^{a}$, Svante Vikingsson ${ }^{b}$, Anders Johansson ${ }^{a}$, Martin Josefsson ${ }^{a, c}$, Henrik Green $^{b, c}$, \\ Johan Dahlén ${ }^{\mathrm{a}}$, Xiongyu $\mathrm{Wu}^{\mathrm{a}^{*}}$, Peter Konradsson ${ }^{\mathrm{a}}$ \\ ${ }^{a}$ Department of Physics, Chemistry and Biology, Linköping University, Sweden \\ ${ }^{b}$ Division of Drug Research, Department of Medical and Health Sciences, Faculty of Health Sciences, \\ Linköping University, Sweden \\ ${ }^{c}$ Department of Forensic Genetics and Forensic Toxicology, National Board of Forensic Medicine, \\ Linköping, Sweden \\ email:xiongyu.wu@liu.se
}

\section{General information}

TLC was performed using $0.25 \mathrm{~mm}$ precoated silica-gel plates (Merck $60 \mathrm{~F}_{254}$ ), detection by UV-abs at $254 \mathrm{~nm} .{ }^{1} \mathrm{H}$ and ${ }^{13} \mathrm{C}$-NMR spectra were recorded on a Varian Mercury $300 \mathrm{MHz}$ instrument $\left(25{ }^{\circ} \mathrm{C}\right.$ in $\mathrm{CDCl}_{3}$ or methanol- $\left.\mathrm{d}_{4}\right)$. HPLC-MS was performed on a Gilson system (Column: Phenomenex C-18, $5 \mu \mathrm{m}, 100$ x 21, $20 \mathrm{~mm}$ and Waters X-Bridge C-8 $2.5 \mu \mathrm{m}, 50 \mathrm{x}$ $4.6 \mathrm{~mm}$ or C-8 $2.5 \mu \mathrm{m}, 50 \times 4.6 \mathrm{~mm}$ for preparative and analytical experiments respectively; using acetonitrile and deionized water with ammonium acetate $(10 \mathrm{mM})$ as mobile phase. Pump: Gilson gradient pump 322; UV/VIS detector: Gilson 155, detection at 215 nm; MS detector: Thermo Finnigan Surveyor MSQ; Gilson Fraction Collector FC204). Flash chromatography was performed using the following silica gel: High purity grade (Merck Grade 9385), pore size $60 \AA, 230-240$ mesh particle size. The reagents were purchased from Sigma-Aldrich and Fluka (TBTU and $\left.\mathrm{BF}_{3}(\mathrm{OEt})_{2}\right)$. The results of the high-resolution mass measurements using LC-QTOF-MS by National Board of Forensic Medicine, Sweden, can be found in the experimental.

\section{3-Amino-1-adamantol (2)}

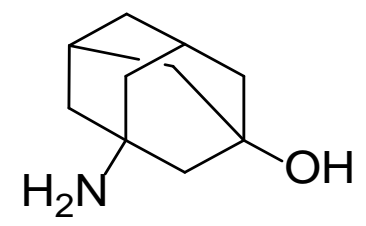

To a round bottom flask containing 1, amantadine hydrochloride (100 mg, $0.53 \mathrm{mmol}$ ) a mixture of concentrated sulfuric acid ( $2 \mathrm{ml}, 37.1 \mathrm{mmol})$ and concentrated nitric acid $(0.2 \mathrm{ml}$, $4.46 \mathrm{mmol}$ ) was added at $0{ }^{\circ} \mathrm{C}$. The mixture was left to stir for two hours at $10{ }^{\circ} \mathrm{C}$. Ice-cold 
water was then carefully added to the reaction mixture, following this addition the reaction mixture was made basic using solid sodium hydroxide until precipitation could be seen. The solution was thereafter filtered and the wet solid collected and dissolved in DCM and left to stir for 30 minutes. Next, the solid was removed from the solution by filtration and washed with DCM. The DCM-solution containing 2 was concentrated to afford compound 2 (70 mg, yield 81\%). ${ }^{1} \mathrm{H}-\mathrm{NMR}\left(\mathrm{CDCl}_{3}, 300 \mathrm{MHz}\right) \delta$ : 2.24-2.16 (m, 2H), 1.62-1.58 (m, 4H), 1.54-1.50 (m, 2H), 1.49-1.43(m, 6H). ${ }^{13} \mathrm{C}-\mathrm{NMR}\left(\mathrm{CDCl}_{3}, 75.4 \mathrm{MHz}\right) \delta: 69.6$ (HOC), 53.9, 50.5, 44.9, 44.2, 34.9, 31.1 (aliphatic $\underline{\mathrm{C}}$ ).

$N$-(3-hydroxyadamantan-1-yl)-1H-indazole-3-carboxamide (3)<smiles>O=C(NC12CC3CC(CC(O)(C3)C1)C2)c1n[nH]c2ccccc12</smiles>

Compound 2 (41 mg, $0.25 \mathrm{mmol}$ ) was dissolved in THF $(15 \mathrm{ml})$. To the solution $\mathrm{Et}_{3} \mathrm{~N}(69 \mu \mathrm{l}$, $0.50 \mathrm{mmol}$ ), indazole-3-carboxylic acid (27 mg, $0.16 \mathrm{mmol}$ ) and TBTU (79 mg, $0.25 \mathrm{mmol}$ ) were added. The reaction mixture was left to stir overnight at room temperature. Concentrated and purified on silica using a mobile phase system of EtOAc/n-heptane (4:1) to give compound 3 (41.5 mg, yield 81\%). $R_{f}=0.38$ (4:1 EtOAc/n-heptane). HRMS (ESI, [M+H] $]^{+}$): Calcd. for $\mathrm{C}_{18} \mathrm{H}_{22} \mathrm{~N}_{3} \mathrm{O}_{2}{ }^{+}$: 312.1707. Found: 312.1709. ${ }^{1} \mathrm{H}-\mathrm{NMR}\left(\mathrm{CD}_{3} \mathrm{OD}, 300 \mathrm{MHz}\right) \delta: 8.18$ (dd, $\mathrm{J}=9.6$ Hz, 1.2 Hz, 1H), 7.55 (dd, J = 9.3 Hz, 1.2 Hz, 1H), 7.47 (s, 1H), 7.40 (m, 1H), 7.23 (m, 1H) 2.34-2.26 (m, 2H), 2.18-2.14 (m, 2H), 2,14-2.08 (m, 4H), 1.80-1.56 (m, 6H). ${ }^{13} \mathrm{C}-\mathrm{NMR}$ $\left(\mathrm{CD}_{3} \mathrm{OD}, 75.4 \mathrm{MHz}\right) \delta: 164.4$ (ㄷNH), 143.0, 140.2, 127.9, 123.4, 122.8, 111.4 (aromatic $\underline{\mathrm{C}}$ ), 69.7 (HOC), 55.6, 55.5, 49.8, 49.7, 44.9, 41.4, 36.1, 32.2 (aliphatic $\underline{\text { C). }}$

\section{$N$-(3-hydroxyadamantan-1-yl)-1-pentyl-1H-indazole-3-carboxamide (4)}

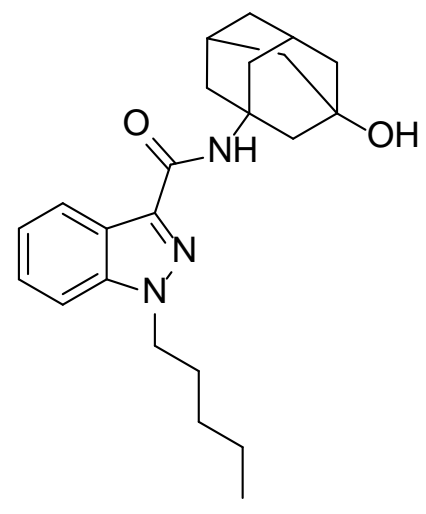


Compound 3 (32 mg, $0.10 \mathrm{mmol}$ ) was dissolved in DMF/THF (1:5, 7.2 ml) and left to stir at 0 ${ }^{\circ} \mathrm{C}$. Following 5 minutes of stirring t-BuOK (17 mg, $0.15 \mathrm{mmol}$ ) was added and the solution was stirred for an additional 15 minutes. Finally 1-Bromopentane (13 $\mu \mathrm{l}, 0.10 \mathrm{mmol})$ was added to the solution, brought to room temperature and stirred overnight. The progression of the reaction was monitored by TLC. Water $(30 \mathrm{ml})$ was added to the solution and extracted using EtOAc (3x20 ml). The combined organic phases were concentrated and the residue was purified on silica using an eluent composition of 2:1 EtOAc/n-heptane to afford compound 4 (35.4 mg, yield 90\%). $R_{f}=0.44$ (2:1 EtOAc/n-heptane). HRMS (ESI, $[\mathrm{M}+\mathrm{H}]^{+}$): Calcd. for $\mathrm{C}_{23} \mathrm{H}_{32} \mathrm{~N}_{3} \mathrm{O}_{2}{ }^{+}$: 382.2490. Found: 382.2483. ${ }^{1} \mathrm{H}-\mathrm{NMR}\left(\mathrm{CDCl}_{3}, 300 \mathrm{MHz}\right) \delta: 8.36$ (dd, J = 8.1 Hz, $\left.1.2 \mathrm{~Hz}, 1 \mathrm{H}\right)$, 7.42-7.37 (m, 2H), 7.25 (m, 1H), 6.88 (br s, 1H), 4.35 (t, J = 6.9 Hz, 2H), 2.37-2.30 (m, 2H), 2.21-2.18 (m, 2H), 2.14-2.10 (m, 4H), 1.93 (dt, J = 7 Hz, 2H), 1.80-1.50 (m, 6H), 1.42-1.24 (m, $4 \mathrm{H}), 0.89$ (t, J = 6.3 Hz, 3H). ${ }^{13} \mathrm{C}-\mathrm{NMR}\left(\mathrm{CDCl}_{3} 75.4 \mathrm{MHz}\right) \delta: 162.3$ (CONH), 141.0, 137.9, 126.7, 123.1, 122.9, 122.5, 109.3 (aromatic 드), 69.4 (으), 54.4, 49.6, 49.5, 44.3, 40.7, 35.1, 30.9, 29.6, 29.0, 22.4, 14.1 (aliphatic $\underline{\text { C)}}$.

\section{N-(4-oxoadamantan-1-yl)-1H-indazole-3-carboxamide (6)}

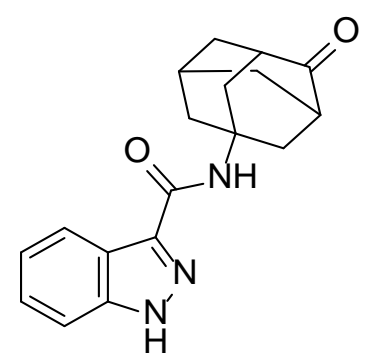

Compound 5 (50 mg, $0.3 \mathrm{mmol}$ ) was dissolved in MeCN (220 $\mu \mathrm{l}, 4.2 \mathrm{mmol}$ ). To the solution boron trifluoride diethyl etherate (114 $\mu \mathrm{l}, 0.9 \mathrm{mmol})$ and TFA (184 $\mu \mathrm{l}, 2.4 \mathrm{mmol})$ were added and the vial was sealed with a cap. The solution was heated at $70{ }^{\circ} \mathrm{C}$ for three hours before being let cool to room temperature and left overnight. The solvents were evaporated prior to the addition of a saturated $\mathrm{NaHCO}_{3}(\mathrm{aq})$ solution $(3 \mathrm{ml})$. Additional water was added and the solution was extracted using chloroform (3x20 ml). The organic phases were concentrated and the crude carboxamide was dissolved in concentrated $\mathrm{HCl}(3 \mathrm{ml})$. The solution was heated for one hour at $150{ }^{\circ} \mathrm{C}$ using microwave irradiation. The solvent was then evaporated. The crude 5-aminoadamantan-2-one was dissolved in THF (10 ml). ${ }^{1}$ Indazole-3-carboxylic acid (32 mg, $0.2 \mathrm{mmol}$ ), TBTU (96 mg, $0.3 \mathrm{mmol}$ ) and $\mathrm{Et}_{3} \mathrm{~N}$ ( $84 \mu \mathrm{l}, 0.6 \mathrm{mmol}$ ) were added to the solution. The reaction mixture was left to stir overnight at room temperature. The solution was concentrated and purified on silica gel using a mobile phase system of EtOAc/n-heptane (4:1) to give 6 (27.8 mg, yield 30\%). $R_{f}=0.57$ (4:1 EtOAc/n-heptane ). ${ }^{1} \mathrm{H}-\mathrm{NMR}\left(\mathrm{CDCl}_{3}, 300 \mathrm{MHz}\right)$ 
$\delta: 10.56$ (s, 1H), 8.27 (m, 1H), 7.54-7.40 (m, 2H), 7.29 (m, 1H), 6.98 (br s, 1H), 2.72-2.64 (m, 2H), 2.58-2.42 (m, 6H), 2.32 (m, 1H), 2.16-1.94 (m, 4H). ${ }^{13} \mathrm{C}-\mathrm{NMR}\left(\mathrm{CD}_{3} \mathrm{OD}, 75.4 \mathrm{MHz}\right) \delta$ : 219.0 (드), 164.7 (ㅇNH), 143.0, 139.9, 127.9, 122.6, 122.5, 122.4, 111.5 (aromatic $\underline{\mathrm{C}}$ ), 52.1, 48.1, 42.9, 41.3, 39.4, 30.2 (aliphatic $\underline{\mathrm{C}}$ ).*

*Results from a crude ${ }^{13} \mathrm{C}-N M R$ where the strongest signals thought to originate from the product were recorded.

$N$-(4-oxoadamantan-1-yl)-1-pentyl-1H-indazole-3-carboxamide (7)

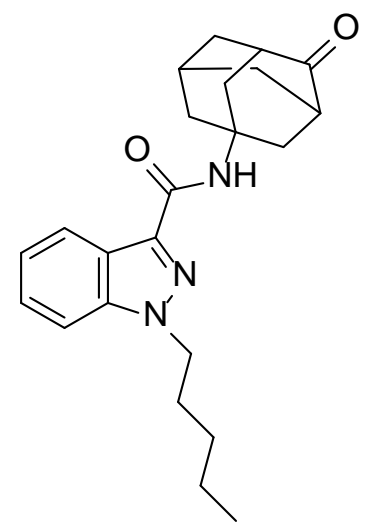

Compound 6 (27.8 mg, $0.09 \mathrm{mmol}$ ) was dissolved in DMF/THF (1:5, 7.2 ml) and left to stir at $0{ }^{\circ} \mathrm{C}$ for five minutes. t-BuOK (15 mg, $0.135 \mathrm{mmol}$ ) was added and the solution was stirred for 15 minutes. As the solution was brought to room temperature 1-bromopentane (11 $\mu$ l, 0.09 mmol) was added and the solution was left to stir overnight. The progression of the reaction was monitored by TLC. Water $(20 \mathrm{ml})$ was added to the solution which was extracted using EtOAc (3x20 ml). The combined organic phases were concentrated and the residue was purified on silica using an eluent composition of 1:1 EtOAc/n-heptane to afford compound 7 (24.6 mg, yield 72\%). $R_{f}=0.53\left(1: 1\right.$ EtOAc/n-heptane ). HRMS (ESI, $\left.[\mathrm{M}+\mathrm{H}]^{+}\right)$: Calcd. for $\mathrm{C}_{23} \mathrm{H}_{30} \mathrm{~N}_{3} \mathrm{O}_{2}{ }^{+}$: 380.2333. Found: 380.2331. ${ }^{1} \mathrm{H}-\mathrm{NMR}\left(\mathrm{CDCl}_{3} 300 \mathrm{MHz}\right) \delta$ : 8.33 (dd, J = 8.1 Hz, $\left.1.2 \mathrm{~Hz}, 1 \mathrm{H}\right)$, 7.42-7.36 (m, 2H), 7.25 (m, 1H), 6.87 (br s, 1H), 4.34 (t, J = 7.1 Hz, 2H) 2.70-2.62 (m, 2H) 2.58-2.38 (m, 6H), 2.31 (m, 1H), 2.16-1.95 (m, 4H), 2.00-1.85 (m, 2H), 1.40-1.24 (m, 4H), 0.88 (t, J = 6.9 Hz, 3H). ${ }^{13} \mathrm{C}-\mathrm{NMR}\left(\mathrm{CDCl}_{3} 75.4 \mathrm{MHz}\right) \delta: 216.7$ (ㄷ), 162.5 (ㅁNH), 141.0, 137.5, 126.8, 123.0, 122.8, 122.7, 109.3 (aromatic C), 50.9, 49.5, 46.7, 42.3, 40.7, 38.5, 29.6, 29.0, 28.9, 22.4, 14.1 (aliphatic $\underline{\text { C)}}$.

$N$-((1s,3R,4s,5S,7s)-4-hydroxyadamantan-1-yl)-1-pentyl-1H-indazole-3-carboxamide (8) and $N$-((1s,3R,4r,5S,7s)-4-hydroxyadamantan-1-yl)-1-pentyl-1H-indazole-3-carboxamide (9) 

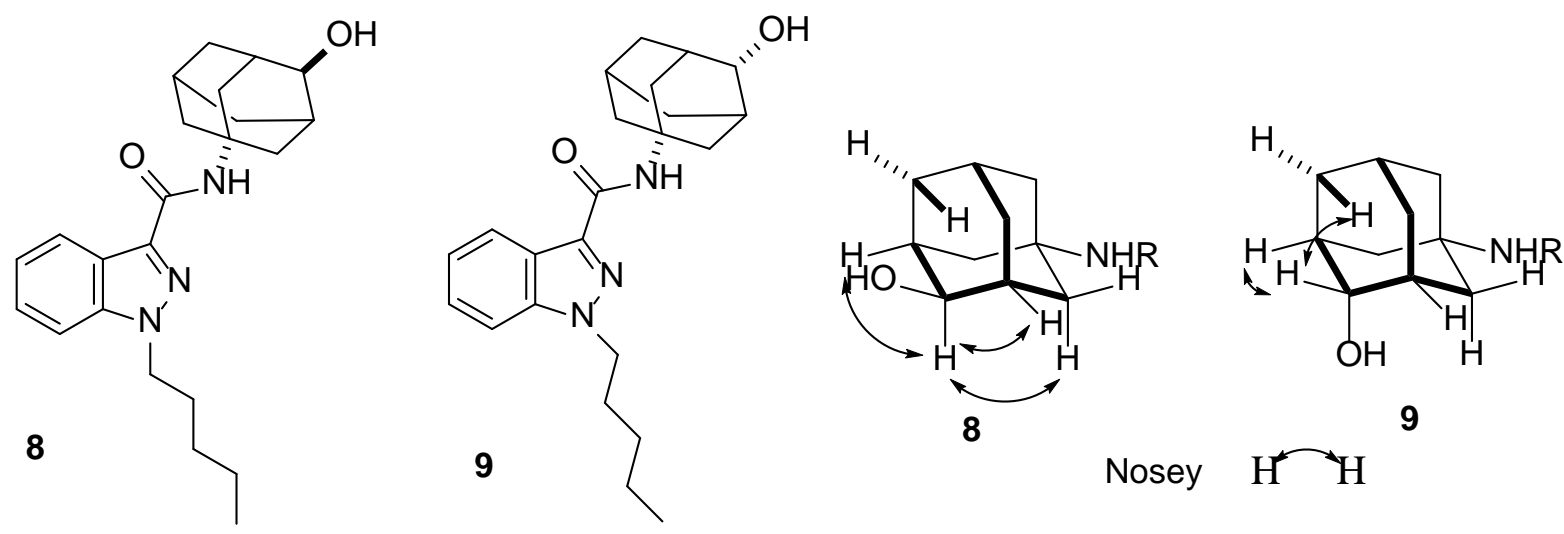

Compound 7 (21.9 mg, $0.058 \mathrm{mmol}$ ) was dissolved in methanol $(10 \mathrm{ml})$. To the solution $\mathrm{NaBH}_{4}$ (15 mg, $0.4 \mathrm{mmol}$ ) was added, the solution was left to stir for one hour at room temperature. The progression of the reaction was monitored using liquid chromatography. Once the reaction had finished the reaction mixture was concentrated prior to the addition of $\operatorname{HCl}(\mathrm{aq})(1 \mathrm{M}, 10$ $\mathrm{ml})$. The acidic solution was extracted using EtOAc (3x10 ml), concentrated and purified by preparative liquid chromatography to give compound 8 (8 mg, yield 36\%) and compound 9 (4.5 mg, yield 20\%). 1D NMR and 2D NMR (HSQC, HMBC, Noesy) were used for the structure elucidation. Compound 8: $R_{f}=0.38$ (1:1 EtOAc/n-heptane). HRMS (ESI, [M+H] $]^{+}$): Calcd. for $\mathrm{C}_{23} \mathrm{H}_{32} \mathrm{~N}_{3} \mathrm{O}_{2}{ }^{+}$: 382.2490. Found: 382.2489. ${ }^{1} \mathrm{H}-\mathrm{NMR}\left(\mathrm{CDCl}_{3}, 300 \mathrm{MHz}\right) \delta$ : 8.36 (dd, $\mathrm{J}=8.1$ Hz, 1.2 Hz, 1H), 7.42-7.38 (m, 2H), 7.24 (m, 1H), 6.81 (br s, 1H), 4.35 (t, J = 7.4 Hz, 2H), 4.02 (m, 1H), 2.34-2.04 (m, 11H), 1.98-1.86 (m, 2H), 1.66-1.50 (m, 2H), 1.42-1.24 (m, 4H), 0.89 (t, $\mathrm{J}=6.9 \mathrm{~Hz}, 3 \mathrm{H}) .{ }^{13} \mathrm{C}-\mathrm{NMR}\left(\mathrm{CDCl}_{3}, 75.4 \mathrm{MHz}\right) \delta: 162.4$ (CONH), 141.0, 137.9, 126.7, 123.1, 122.9, 122.5, 109.3 (aromatic $\underline{\mathrm{C}}), 73.6$ (으), 51.2, 49.5, 42.1, 40.4, 35.5, 30.1, 29.6, 29.1, 28.9, 22.4, 14.1 (aliphatic $\underline{\text { ) }}$.

Compound 9: $R_{f}=0.40$ (1:1 EtOAc/n-heptane). HRMS (ESI, $\left.[\mathrm{M}+\mathrm{H}]^{+}\right)$: Calcd. for $\mathrm{C}_{23} \mathrm{H}_{32} \mathrm{~N}_{3} \mathrm{O}_{2}{ }^{+}$: 382.2490. Found: 382.2492. ${ }^{1} \mathrm{H}-\mathrm{NMR}\left(\mathrm{CDCl}_{3}, 300 \mathrm{MHz}\right) \delta: 8.37(\mathrm{~d}, \mathrm{~J}=8.1$ Hz, 1H), 7.42-7.36 (m, 2H), 7.24 (m, 1H), 6.82 (s, 1H), 4.35 (t, J = 7.4 Hz, 2H), 3.83 (m, 1H), 2.50-2.00 (m, 9H), 2.00-1.86 (m, 2H), 1.92-1.82 (m, 2H), 1.72-1.60 (m, 2H), 1.42-1.24 (m, 4H), 0.89 (t, J = 6.9 Hz, 3H). ${ }^{13} \mathrm{C}-\mathrm{NMR}\left(\mathrm{CDCl}_{3} 75.4 \mathrm{MHz}\right) \delta: 162.3$ (CONH), 141.0, 137.9, 126.6, 123.2, 122.9, 122.5, 109.3 (aromatic ㄷ) 73.1 (으), 51.3, 49.5, 41.6, 36.2, 35.6, 35.3, 29.6, 29.0, 28.3, 22.4, 14.1 (aliphatic $\underline{\mathrm{C}}$ ). 
Appendix:

${ }^{1} \mathrm{H}-\mathrm{NMR}$ and ${ }^{13} \mathrm{C}-\mathrm{NMR}$ of compound 4
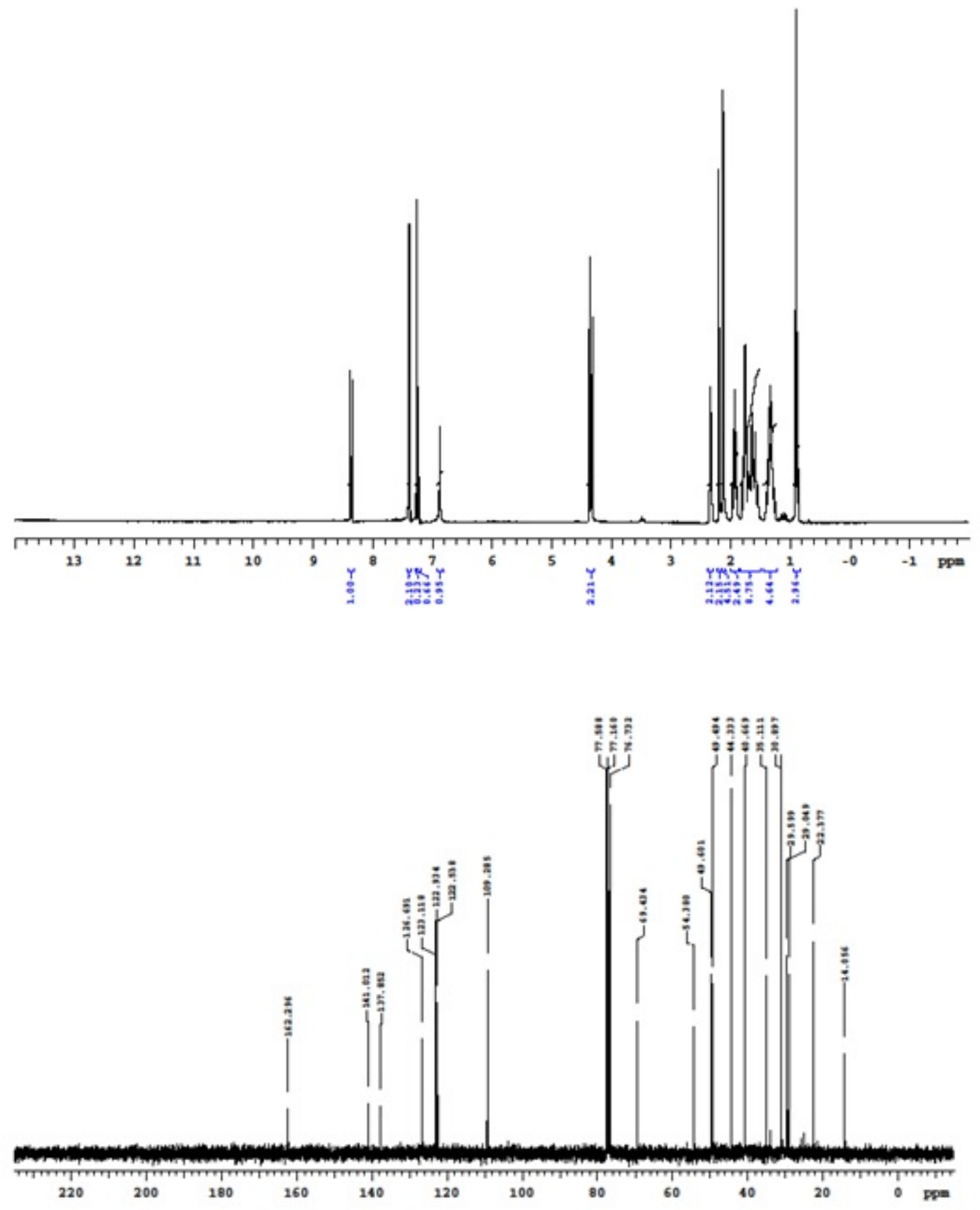
${ }^{1} \mathrm{H}$-NMR and ${ }^{13} \mathrm{C}-\mathrm{NMR}$ of compound 7
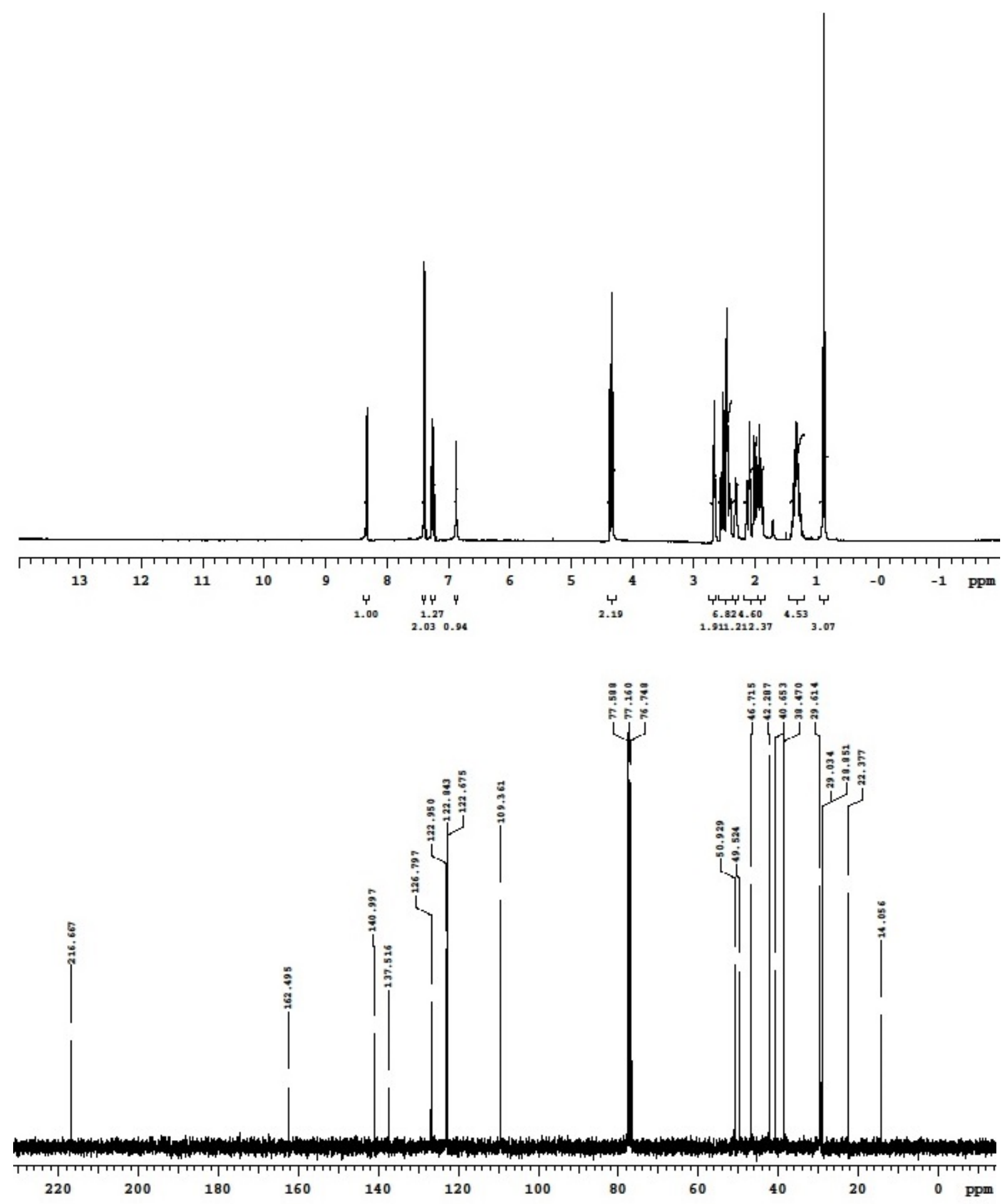
${ }^{1} \mathrm{H}$-NMR and ${ }^{13} \mathrm{C}-\mathrm{NMR}$ of compound $\mathbf{8}$
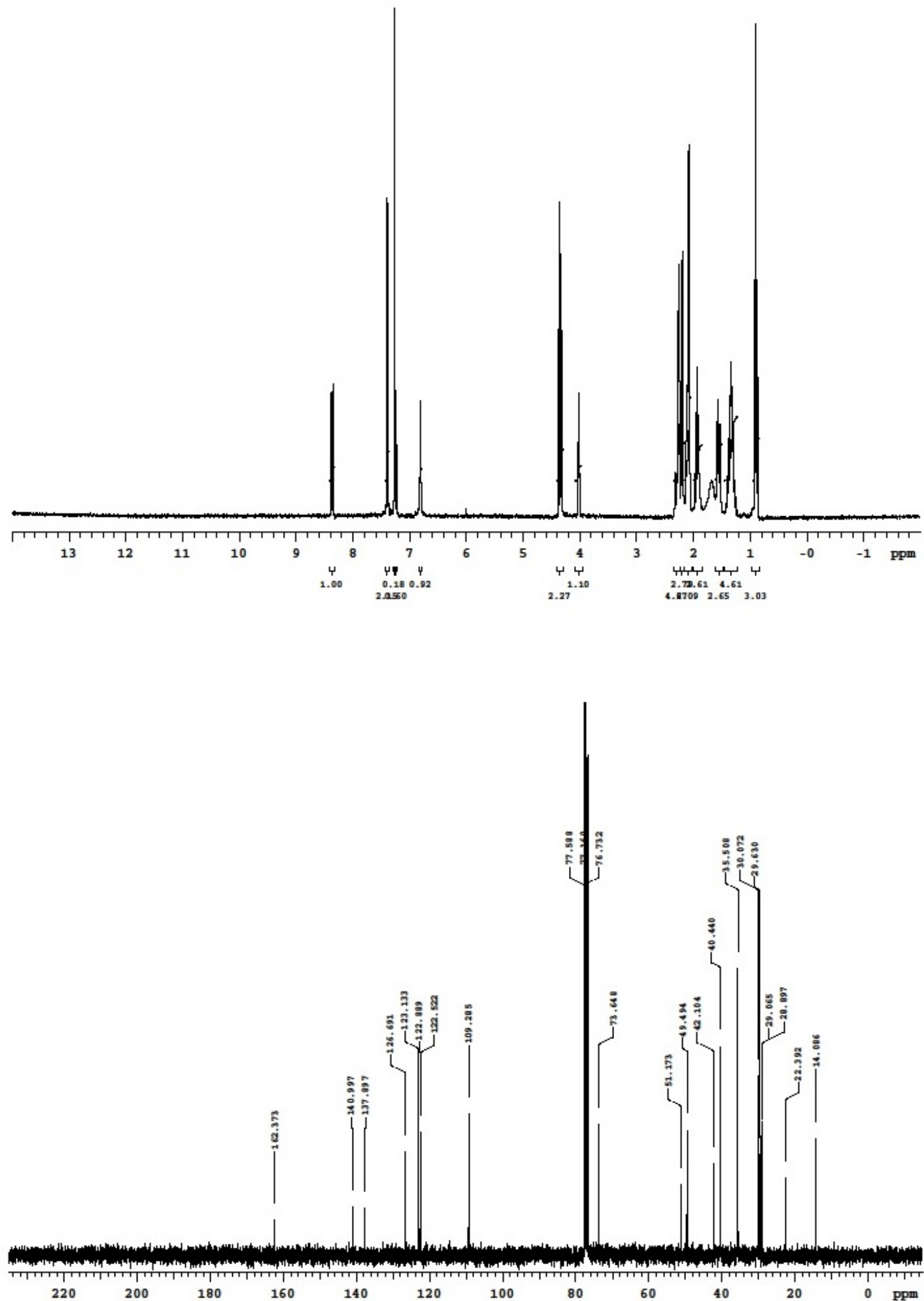
${ }^{1} \mathrm{H}$-NMR and ${ }^{13} \mathrm{C}$-NMR of compound 9
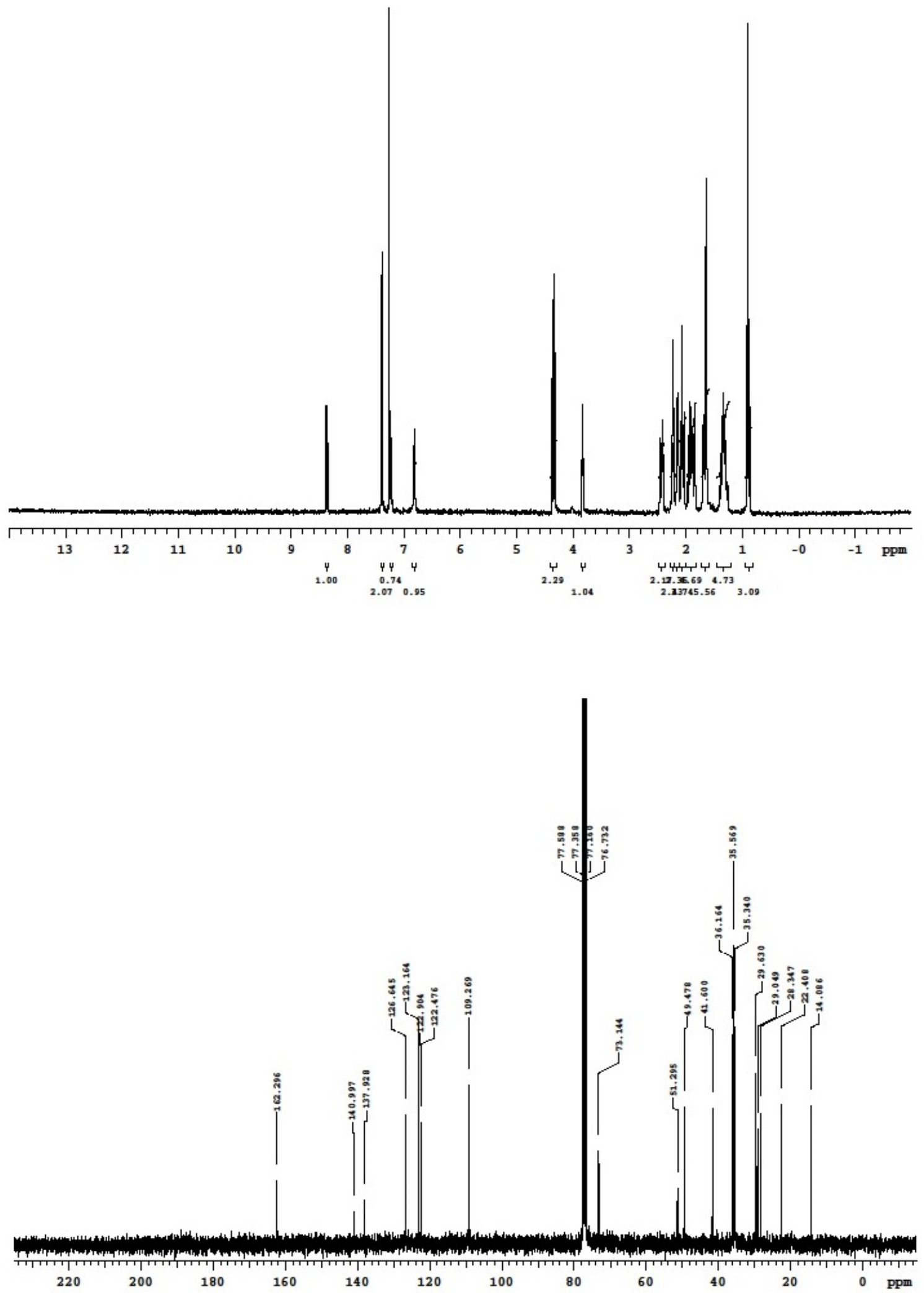